\title{
Techniques and Behaviors Associated with Exemplary Inpatient General Medicine Teaching: An Exploratory Qualitative Study
}

\author{
Nathan Houchens, $\mathrm{MD}^{1,2^{*}}$, Molly Harrod, $\mathrm{PhD}^{3}$, Stephanie Moody, $\mathrm{PhD}^{4}$, Karen E. Fowler, MPH ${ }^{3}$, Sanjay Saint, MD, MPH ${ }^{1,2}$
}

${ }^{\top}$ Medicine Service, Veterans Affairs Ann Arbor Healthcare System, Ann Arbor, Michigan; '2Department of Internal Medicine, University of Michigan Medical School, Ann Arbor, Michigan; 'Veterans Affairs Center for Clinical Management Research, Veterans Affairs Ann Arbor Healthcare System, Ann Arbor, Michigan; ${ }^{4}$ Department of English and Sweetland Center for Writing, University of Michigan, Ann Arbor, Michigan.

\begin{abstract}
BACKGROUND: Clinician educators face numerous obstacles to their joint mission of facilitating high-quality learning while also delivering patient-centered care. Such challenges necessitate increased attention to the work of exemplary clinician educators, their respective teaching approaches, and the experiences of their learners.
\end{abstract}

OBJECTIVE: To describe techniques and behaviors utilized by clinician educators to facilitate excellent teaching during inpatient general medicine rounds.

DESIGN: An exploratory qualitative study of inpatient teaching conducted from 2014 to 2015.

SETTING: Inpatient general medicine wards in 11 US hospitals, including university-affiliated hospitals and Veterans Affairs medical centers.

PARTICIPANTS: Participants included 12 exemplary clinician educators, 57 of their current learners, and 26 of their former learners.

MEASUREMENTS: In-depth, semi-structured interviews of exemplary clinician educators, focus group discussions with their current and former learners, and direct observations of clinical teaching during inpatient rounds.

RESULTS: Interview data, focus group data, and observational field notes were coded and categorized into broad, overlapping themes. Each theme elucidated a series of actions, behaviors, and approaches that exemplary clinician educators consistently demonstrated during inpatient rounds: (1) they fostered positive relationships with all team members by building rapport, which in turn created a safe learning environment; (2) they facilitated patient-centered teaching points, modeled excellent clinical exam and communication techniques, and treated patients as partners in their care; and (3) they engaged in coaching and collaboration through facilitation of discussion, effective questioning strategies, and differentiation of learning among team members with varied experience levels.

CONCLUSION: This study identified consistent techniques and behaviors of excellent teaching during inpatient general medicine rounds. Journal of Hospital Medicine 2017;12:503509. (C) 2017 Society of Hospital Medicine
Clinician educators face numerous obstacles to their joint mission of facilitating learning while also ensuring high-quality and patient-centered care. Time constraints, including the institution of house officer duty hour limitations, ${ }^{1}$ shorter lengths of stay for hospitalized patients, ${ }^{2}$ and competing career responsibilities, combine to create a dynamic learning environment. Additionally, clinician educators must balance the autonomy of their learners with the safety of their patients. They must teach to multiple learning levels and work collaboratively with multiple disciplines to foster an effective teambased approach to patient care. Yet, many clinician educators have no formal training in pedagogical methods. ${ }^{3}$ Such challenges necessitate increased attention to the work of excellent clinician educators and their respective teaching approaches.

\footnotetext{
*Address for correspondence and reprint requests: Nathan Houchens, MD, University of Michigan and Veterans Affairs Ann Arbor Healthcare System, 2215 Fuller Road, Mail Code 111, Ann Arbor, Ml 48105; Telephone: 734-845-5922; Fax: 734-913-0883; E-mail: nathanho@med.umich.edu

Additional Supporting Information may be found in the online version of this article.

Received: October 29 2016; Revised: December 12, 2016; Accepted: December 21, 2016
}

2017 Society of Hospital Medicine DOI 10.12788/jhm.2763
Many studies of clinical teaching rely primarily on survey data of attributes of good clinical teachers. ${ }^{3.7}$ While some studies have incorporated direct observations of teaching ${ }^{8,9}$ or interviews with clinician educators or learners, ${ }^{10,11}$ few have incorporated multiple perspectives from the current team and from former learners in order to provide a comprehensive picture of team-based learning. ${ }^{12}$

The goal of this study was to gain a thorough understanding, through multiple perspectives, of the techniques and behaviors used by exemplary educators within actual clinical environments. We studied attitudes, behaviors, and approaches of 12 such inpatient clinician educators.

\section{METHODS}

\section{Study Design and Sampling}

This was a multisite study using an exploratory qualitative approach to inquiry. This approach was used to study the techniques and behaviors of excellent attendings during inpatient general medicine rounds. A modified snowball sampling approach ${ }^{13}$ was used, meaning individuals known to one member of the research team (SS) were initially contacted and asked to identify clinician educators (also referred to as attendings) for potential inclusion in the study. In an effort to identify attendings from a broad range of med- 
ical schools, the "2015 U.S. News and World Report Top Medical Schools: Research" rankings ${ }^{14}$ were also reviewed, with priority given to the top 25 , as these are widely used to represent the best US hospitals. In an attempt to invite attendings from diverse institutions, additional medical schools not in the top 25 as well as historically black medical schools were also included. Division chiefs and chairs of internal medicine and/or directors of internal medicine residency programs at these schools were contacted and asked for recommendations of attendings, both within and outside their institutions, who they considered to be great inpatient teachers. In addition, key experts who have won teaching awards or were known to be specialists in the field of medical education were asked to nominate one or two other outstanding attendings.

By using this sampling method, 59 potential participants were identified. An internet search was conducted to obtain information about the potential participants and their institutions. Organizational characteristics such as geographic location, hospital size and affiliation, and patient population, as well as individual characteristics such as gender, medical education and training, and educational awards received were considered so that a diversity of organizations and backgrounds was represented. The list was narrowed down to 16 attendings who were contacted via e-mail and asked to participate. Interested participants were asked for a list of their current team members and 6 to 10 former learners to contact for interviews and focus groups. Former learners were included in an effort to better understand lasting effects on learners from their exemplary teaching attendings. A total of 12 attending physicians agreed to participate (Table 1). Literature on field methods has shown that 12 interviews are found to be adequate in accomplishing data saturation. ${ }^{15}$ Although 2 attendings were located at the same institution, we decided to include them given that both are recognized as master clinician educators and were each recommended by several individuals from various institutions. Hospitals were located throughout the US and included both university-affiliated hospitals and Veterans Affairs medical centers. Despite efforts to include physicians from historically black colleges and universities, only one attending was identified, and they declined the request to participate.

\section{Data Collection}

Observations. The one-day site visits were mainly conducted by two research team members, a physician (SS) and a medical anthropologist $(\mathrm{MH})$, both of whom have extensive experience in qualitative methods. Teams were not uniform but were generally comprised of 1 attending, 1 senior medical resident, 1 to 2 interns, and approximately 2 medical students. Occasionally, a pharmacist, clinical assistant, or other health professional accompanied the team on rounds. Not infrequently, the bedside nurse would explicitly be included in the discussion regarding his or her specific patient. Each site visit began with observing attendings $(\mathrm{N}=12)$ and current learners $(\mathrm{N}=57)$ during rounds. Each research team member recorded their own observations via handwritten field notes, paying particular attention to group interactions, teaching approach, conversations occurring within and peripheral to the team, patient-team interactions, and the physical environment. By standing outside of the medical team circle and remaining silent during rounds, research team members remained unobtrusive to the discussion and process of rounds. Materials the attendings used during their teaching rounds were also documented and collected. Rounds generally lasted 2 to 3 hours. After each site visit, the research team met to compare and combine field notes.

Interviews and Focus Groups. The research team then conducted individual, semi-structured interviews with the attendings, focus groups with their current team $(\mathrm{N}=46)$, and interviews or focus groups with their former learners $(\mathrm{N}=26$; Supplement 1). Eleven of the current team members observed during rounds were unable to participate in the focus groups due to clinical duties. Because the current learners who participated in the focus groups were also observed during rounds, the research team was able to ask them open-ended questions regarding teaching rounds and their roles as learners within this environment. Former learners who were still at the hospital participated in separate focus groups or interviews. Former learners who were no longer present at the hospital were contacted by telephone and individually interviewed by one research team member $(\mathrm{MH})$. All interviews and focus groups were audio-recorded and transcribed.

This study was determined to be exempt by the University of Michigan Institutional Review Board. All participants were informed that their participation was completely voluntary and that they could terminate their involvement at any time.

\section{Data Analysis}

Data were analyzed using a thematic analysis approach. ${ }^{16}$ Thematic analysis entails reading through the data to identify patterns (and create codes) that relate to behaviors, experiences, meanings, and activities. Once patterns have been identified, they are grouped according to similarity into themes, which help to further explain the findings. ${ }^{17}$

After the first site visit was completed, the research team members that participated ( $\mathrm{SS}$ and $\mathrm{MH}$ ) met to develop initial ideas about meanings and possible patterns. All transcripts were read by one team member $(\mathrm{MH})$ and, based on review of the data, codes were developed, defined, and documented in a codebook. This process was repeated after every site visit using the codebook to expand or combine codes and refine definitions as necessary. If a new code was added, the previously coded data were reviewed to apply the new code. NVivo® 10 software (QSR International; Melbourne, Australia) was used to manage the data.

Once all field notes and transcripts were coded $(\mathrm{MH})$, the code reports, which list all data described within a specific code, were run to ensure consistency and identify relationships between codes. Once coding was verified, codes were 
TABLE 1. Characteristics of Selected Attendings

\begin{tabular}{|c|c|c|c|c|}
\hline Gender & Institution ${ }^{a}$ & Region & Top 25b & Select Awards ${ }^{c}$ \\
\hline Male & $\begin{array}{l}\text { University of California, San Francisco; } \\
\text { San Francisco VA Medical Center }\end{array}$ & West & Yes & $\begin{array}{l}\text { Kaiser Award for Teaching Excellence, University of California, San Francisco } \\
\text { National Alpha Omega Alpha Robert J. Glaser Distinguished Teaching Award }\end{array}$ \\
\hline Female & University of Chicago Pritzker School of Medicine & Midwest & Yes & Pre-Clinical Teacher of the Year Award, University of Chicago \\
\hline Female & University of Michigan & Midwest & Yes & Marvin Pollard Award for Outstanding Teaching of Residents, University of Michigan \\
\hline Male & $\begin{array}{l}\text { Northwestern University; Jesse Brown VA Medical } \\
\text { Center }\end{array}$ & Midwest & Yes & $\begin{array}{l}\text { Outstanding Clinical Teacher Award } \\
\text { Robert J. Winter Clinical Teacher Award } \\
\text { George Joost Award for Outstanding Clinical Teacher } \\
\text { "Teaching Hall of Fame" Award from Northwestern University }\end{array}$ \\
\hline Male & Massachusetts General Hospital & Northeast & Yes & $\begin{array}{l}\text { Alfred Kranes Award, Excellence in Clinical Teaching, Massachusetts General Hospital } \\
\text { Best Clinical Instructor Award, Harvard Medical School } \\
\text { Society of Hospital Medicine's Award for Excellence in Teaching }\end{array}$ \\
\hline Male & Cleveland Clinic & Midwest & Yes & $\begin{array}{l}\text { 5-time recipient Cleveland Clinical Department of Medicine Teacher of the Year Award } \\
\text { Bruce Hubbard Stewart Fellowship Award }\end{array}$ \\
\hline Male & $\begin{array}{l}\text { Rush University; } \\
\text { Cook County Chicago }\end{array}$ & Midwest & No & $\begin{array}{l}\text { 3-time recipient Sir William Osler Award for Teaching of Internal Medicine, Stroger Hospital } \\
\text { 4-time recipient Division of Hospital Medicine's Cooker Award for Inpatient Medicine Teaching } \\
\text { and Team Leadership } \\
\text { 2-time recipient Department of Medicine Medical Student Education Award }\end{array}$ \\
\hline Male & University of Washington; Seattle VA Medical Center & West & Yes & $\begin{array}{l}\text { Marvin Turck Outstanding Teaching Award } \\
\text { Teacher Superior in Perpetuity Award } \\
\text { Margaret Anderson Award } \\
\text { Attending of the Year } \\
\text { Paul Beeson Teaching Award } \\
\text { National Alpha Omega Alpha Distinguished Teacher Award }\end{array}$ \\
\hline Male & Baylor College of Medicine & South & Yes & $\begin{array}{l}\text { 6-time recipient Department of Internal Medicine Outstanding Faculty Educator Award } \\
\text { 2-time recipient Baylor College of Medicine Medical School Outstanding Faculty Award } \\
\text { Baylor College of Medicine Medical School "Teaching Hall of Fame" }\end{array}$ \\
\hline Female & University of Wisconsin-Madison & Midwest & No & $\begin{array}{l}\text { UW-Madison Chancellor's Hilldale Award for Excellence in Teaching } \\
\text { School of Medicine and Public Health's Dean's Teaching Award }\end{array}$ \\
\hline Male & $\begin{array}{l}\text { University of California, San Francisco; } \\
\text { San Francisco VA Medical Center }\end{array}$ & West & Yes & $\begin{array}{l}\text { Kaiser Award for Teaching Excellence at University of California, San Francisco } \\
\text { University of California, San Francisco Distinction in Teaching Award }\end{array}$ \\
\hline Male & Tulane University & South & No & $\begin{array}{l}\text { 6-time recipient Tulane's Attending of the Year Award } \\
\text { Society of Hospital Medicine's Education Award } \\
\text { Accreditation Council for Graduate Medical Education's Parker Palmer Courage to Teach Award } \\
\text { Association of American Medical Colleges' Robert J. Glaser Distinguished Teacher Award } \\
\text { American College of Physician's Walter J. McDonald Award } \\
\text { Society of General Internal Medicine's Mid-Career Mentorship Award }\end{array}$ \\
\hline
\end{tabular}

anstitution at time of project participation.

'Affiliated medical school ranked in the Top 25 on the U.S. News \& World Report Medical School Rankings 2015.

'All of the attendings have earned multiple teaching awards, with several earning 30 or more. Only selected awards are listed here.

grouped based on similarities and relationships into salient themes by 3 members of the research team $(\mathrm{NH}, \mathrm{MH}$, and $\mathrm{SM})$. Themes, along with their supporting codes, were then further defined to understand how these attendings worked to facilitate excellent teaching in clinical settings.

\section{RESULTS}

The coded interview data and field notes were categorized into broad, overlapping themes. Three of these major themes include (1) fostering positive relationships, (2) patient-centered teaching, and (3) collaboration and coaching. Table 2 lists each theme, salient behaviors, examples, and selected quotes that further elucidate its meaning.

\section{Fostering Positive Relationships}

Attending physicians took observable steps to develop positive relationships with their team members, which in turn created a safe learning environment. For instance, attendings used learners' first names, demonstrated interest in their well-being, deployed humor, and generally displayed informal actions-uncrossed arms, "fist bump" when recognizing learners' success, standing outside the circle of team mem- 
TABLE 2. Key Themes, Behaviors, Techniques, and Selected Quotes of Effective Clinical Teaching

\begin{tabular}{|c|c|c|c|}
\hline Themes & Behaviors & Techniques & Selected Quotes \\
\hline \multirow[t]{4}{*}{$\begin{array}{l}\text { Fostering Positive } \\
\text { Relationships }\end{array}$} & Builds rapport with learners & $\begin{array}{l}\text { Uses learners' first names, shows interest } \\
\text { in learners' well-being and personal lives; } \\
\text { deploys lighthearted humor; assumes casual, } \\
\text { nonthreatening stance during interactions }\end{array}$ & \multirow[t]{4}{*}{$\begin{array}{l}\text { "... You need to make people feel comfortable about putting their } \\
\text { thoughts out so that you can actually say no or yes and correct them, and } \\
\text { if you make them comfortable saying that, they will come up with more } \\
\text { questions that will trigger a good learning environment." (Former Learner) }\end{array}$} \\
\hline & $\begin{array}{l}\text { Creates a safe, supportive, and } \\
\text { challenging learning environment }\end{array}$ & $\begin{array}{l}\text { Responds thoughtfully to learners' input; } \\
\text { encourages learners to ask questions and admit } \\
\text { uncertainty; sets high expectations but supports } \\
\text { learners in reaching them; consistently gives } \\
\text { encouraging feedback }\end{array}$ & \\
\hline & $\begin{array}{l}\text { Positions self as lifelong learner } \\
\text { alongside team members }\end{array}$ & $\begin{array}{l}\text { Acknowledges that medicine can be illogical and } \\
\text { ambiguous; admits uncertainty; demonstrates } \\
\text { humility and self-deprecation; encourages learners } \\
\text { to question attendings' ideas }\end{array}$ & \\
\hline & $\begin{array}{l}\text { Includes other health } \\
\text { professionals as part of the team }\end{array}$ & $\begin{array}{l}\text { Greets staff members by name; uses humor } \\
\text { and builds rapport with staff members; includes } \\
\text { specialty care providers in conversations with } \\
\text { learners }\end{array}$ & \\
\hline \multirow[t]{4}{*}{ Patient-Centered Teaching } & $\begin{array}{l}\text { Develops patient-specific teaching } \\
\text { points }\end{array}$ & $\begin{array}{l}\text { Knows patient information well; develops questions } \\
\text { related to current patients; focuses teaching points } \\
\text { on patients' needs both in and out of the hospital }\end{array}$ & \multirow[t]{4}{*}{$\begin{array}{l}\text { "I think she does a really great job of involving the patient in any decisions } \\
\text { that are going to be made and making sure that she gets like accordance } \\
\text { with the patient or at least trying to and having good conversations with } \\
\text { them to achieve that." (Current Learner) }\end{array}$} \\
\hline & Treats patients as partners & $\begin{array}{l}\text { Greets patients by name; answers questions; uses } \\
\text { lay language to explain complex medical concepts; } \\
\text { reflects on patients' input; includes patients in } \\
\text { discussions and plans of care }\end{array}$ & \\
\hline & $\begin{array}{l}\text { Models clinical skills and } \\
\text { communication techniques }\end{array}$ & $\begin{array}{l}\text { Personally demonstrates excellent physical } \\
\text { examination and communication skills with patients; } \\
\text { varies which techniques to emphasize based on the } \\
\text { changing needs of the patient }\end{array}$ & \\
\hline & $\begin{array}{l}\text { Uses body language and physical } \\
\text { touch to demonstrate empathy }\end{array}$ & $\begin{array}{l}\text { Touches the patient on shoulder or arm to } \\
\text { demonstrate comfort; kneels or sits at bedside } \\
\text { when talking with patient; helps patient sit up or } \\
\text { move positions }\end{array}$ & \\
\hline \multirow[t]{4}{*}{ Collaboration and Coaching } & Facilitates discussion to foster learning & $\begin{array}{l}\text { Uses lecture sparingly; develops interactional } \\
\text { teaching points; encourages learners to work } \\
\text { together; involves all learners in patient care }\end{array}$ & \multirow{4}{*}{$\begin{array}{l}\text { "They gauge where your knowledge is and then sort of put themselves in } \\
\text { your brain and lead you down the path. They don't start the questions at } \\
\text { a higher level such that you would be like, I just don't know that. Instead, } \\
\text { they start slowly and they sort of leave a trail of breadcrumbs for you to } \\
\text { follow so that you're making connections all along the way. And you come } \\
\text { out of that conversation feeling good because you came to the right place } \\
\text { in the end." (Current Learner) }\end{array}$} \\
\hline & Uses Socratic questioning & $\begin{array}{l}\text { Uses varied questioning techniques to facilitate } \\
\text { learners' thinking; guides learners with questions as } \\
\text { they develop plans of care; uses questions to offer } \\
\text { second thoughts without second guessing }\end{array}$ & \\
\hline & Makes thought processes explicit & $\begin{array}{l}\text { Emphasizes thinking processes over content } \\
\text { knowledge (ie, how to think vs what to think); } \\
\text { verbalizes thought processes to model thinking }\end{array}$ & \\
\hline & $\begin{array}{l}\text { Differentiates learning levels and } \\
\text { team roles }\end{array}$ & $\begin{array}{l}\text { Tailors questions to learners' educational levels, } \\
\text { knowledge, and experience; encourages team } \\
\text { members to play various roles and execute different } \\
\text { tasks depending on their experience }\end{array}$ & \\
\hline
\end{tabular}

bers and leaning in to listen-during learner interactions. Attendings also made it a priority to get to know individuals on a personal level. As one current learner put it, "He asks about where we are from. He will try to find some kind of connection that he can establish with not only each of the team members but also with each of the patients."

Additionally, attendings built positive relationships with their learners by responding thoughtfully to their input, even when learners' evaluations of patients required mod- ification. In turn, learners reported feeling safe to ask questions, admit uncertainty, and respectfully disagree with their attendings. As one attending reflected, "If I can get them into a place where they feel like the learning environment is someplace where they can make a mistake and know that that mistake does not necessarily mean that it's going to cost them in their evaluation part, then I feel like that's why it's important."

To build rapport and create a safe learning environment, 
attendings used a number of strategies to position themselves as learners alongside their team members. For instance, attendings indicated that they wanted their ideas questioned because they saw it as an opportunity to learn. Moreover, in conversations with learners, attendings demonstrated humility, admitting when they did not know something. One former learner noted, "There have been times when he has asked [a] question....nobody knows and then he admits that he doesn't know either. So everybody goes and looks it up... The whole thing turns out to be a fun learning experience."

Attendings demonstrated respect for their team members' time by reading about patients before rounds, identifying learning opportunities during rounds, and integrating teaching points into the daily work of patient care. Teaching was not relegated exclusively to the conference room or confined to the traditional "chalk talk" before or after rounds but rather was assimilated into daily workflow. They appeared to be responsive to the needs of individual patients and the team, which allowed attendings to both directly oversee their patients' care and overcome the challenges of multiple competing demands for time. The importance of this approach was made clear by one current learner who stated "....she does prepare before, especially you know on call days, she does prepare for the new patients before coming in to staff, which is really appreciated... it saves a lot of time on rounds."

Attendings also included other health professionals in team discussions. Attendings used many of the same relationship-building techniques with these professionals as they did with learners and patients. They consistently asked these professionals to provide insight and direction in patients' plans of care. A former learner commented, "He always asks the [nurse] what is her impression of the patient... he truly values the [nurse's] opinion of the patient." One attending reiterated this approach, stating "I don't want them to think that anything I have to say is more valuable than our pharmacist or the [nurse]."

\section{Patient-Centered Teaching}

Attending physicians modeled numerous teaching techniques that focused learning around the patient. Attendings knew their patients well through review of the medical records, discussion with the patient, and personal examination. This preparation allowed attendings to focus on key teaching points in the context of the patient. One former learner noted, "He tended to bring up a variety of things that really fit well into the clinical scenario. So whether that is talking about what is the differential for a new symptom that just came up for this patient or kind of here is a new paper talking about this condition or maybe some other pearl of physical exam for a patient that has a certain physical condition."

Attendings served as effective role models by being directly involved in examining and talking with patients as well as demonstrating excellent physical examination and communication techniques. One current learner articulated the importance of learning these skills by observing them done well: "I think he teaches by example and by doing, again, those little things: being attentive to the patients and being very careful during exams...I think those are things that you teach people by doing them, not by saying you need to do this better during the patient encounter."

\section{Collaboration and Coaching}

Attending physicians used varied collaboration and coaching techniques to facilitate learning across the entire care team. During rounds, attendings utilized visual aids to reinforce key concepts and simplify complex topics. They also collaborated by using discussion rather than lecture to engage with team members. For instance, attendings used Socratic questioning, asking questions that lead learners through critical thinking and allow them to solve problems themselves, to guide learners' decision-making. One former learner reported, "He never gives you the answer, and he always asks your opinion; 'So what are your thoughts on this?"

Coaching for success, rather than directing the various team members, was emphasized. Attendings did not wish to be seen as the "leaders" of the team. During rounds, one attending was noted to explain his role in ensuring that the team was building connections with others: "When we have a bad outcome, if it feels like your soul has been ripped out, then you've done something right. You've made that connection with the patient. My job, as your coach, was to build communication between all of us so we feel vested in each other and our patients."

Attendings also fostered clinical reasoning skills in their learners by encouraging them to verbalize their thought processes aloud in order to clarify and check for understanding. Attendings also placed emphasis not simply on memorizing content but rather prioritization of the patient's problems and thinking step by step through individual medical problems. One current learner applauded an attending who could "come up with schematics of how to approach problems rather than feeding us factual information of this paper or this trial."

Additionally, attendings facilitated learning across the entire care team by differentiating their teaching to meet the needs of multiple learning levels. While the entire team was explicitly included in the learning process, attendings encouraged learners to play various roles, execute tasks, and answer questions depending on their educational level. Attendings positioned learners as leaders of the team by allowing them to talk without interruption and by encouraging them to take ownership of their patients' care. One former learner stated, "She set expectations...we would be the ones who would be running the team, that you know it would very much be our team and that she is there to advise us and provide supervision but also safety for the patients as well."

\section{CONCLUSION}

This study reveals the complex ways effective attendings build rapport, create a safe learning environment, utilize patient-centered teaching strategies, and engage in collab- 
TABLE 3. Key Strategies in Exemplary Clinical Teaching

Foster Positive Relationships

Address team members by their first names.

Get to know team members by asking about their life experiences and being open about your own.

Use humor to make rounds more informal and enjoyable; self-deprecating humor is often effective.

When team members are presenting, let them talk without interruption.

Position yourself as a member of the team rather than the leader of the team.

Encourage the view that mistakes are critical for learning by using your own past mistakes to illustrate teaching.

Admit when you do not know something and share how you intend to find out about it.

Include other health professionals in team discussions, give them full respect, and seek their valuable insights and direction in patients' plans of care.

Patient-Centered Teaching

Prepare for rounds by reviewing medical records, anticipating possible stumbling points, identifying key teaching points, and finding articles to suggest to the team.

Conduct rounds in a timely fashion, aiding the team members' time management.

Build rapport with your patients. Greet them by name, engage them with nonmedical jokes or conversation, explain complicated medical concepts, help patients change positions during examinations, and empathize with their discomfort.

Nonverbal communication is important. A touch, a smile, and a bit of humility can go a long way. Sit down so you are at eye level when speaking with patients. Model these skills for the team.

Plan for the patient's future outside of the hospital. Encourage your team to start thinking about the patient's departure right at admission. Include thoughts about insurance, transportation, social support, contact information, and follow-up.

Collaboration and Coaching

Instead of fact-based lectures to memorize, engage team members in discussions about a few key points. Emphasize thinking process over content knowledge.

Ask team members to explain their answers to questions and how they arrived at a particular conclusion.

Use the Socratic method of questioning to explore team members' understanding. This will allow you to facilitate their journey toward the best answers.

Share your clinical reasoning with the team to help build their analytical frameworks.

Recognize differences in your team members' learning levels and adapt your discussions accordingly. Engage all members of the team in the learning process

Don't ask team members questions you know they cannot answer. Provide them with challenges they can fulfill and learn from.

oration and coaching with all members of the team. These findings provide a framework of shared themes and their salient behaviors that may influence the success of inpatient general medicine clinician educators (Table 3 ).

There is a broad and voluminous literature on the subject of outstanding clinical teaching characteristics, much of which has shaped various faculty development curricula for decades. This study sought not to identify novel approaches of inpatient teaching necessarily but rather to closely examine the techniques and behaviors of clinician educators identified as exemplary. The findings affirm and reinforce the numerous, well-documented lists of personal attributes, techniques, and behaviors that resonate with learners, including creating a positive environment, demonstrating enthusiasm and interest in the learner, reading facial expressions, being student-centered, maintaining a high level of clinical knowledge, and utilizing effective communication skills. ${ }^{18-24}$ The strengths of this study lie within the nuanced and rich observations and discussions that move beyond learners' Likert scale evaluations and responses. ${ }^{3-7,12}$ Input was sought from multiple perspectives on the care team, which provided detail from key stakeholders. Out of these comprehensive data arose several conclusions that extend the research literature on medical education.

In their seminal review, Sutkin et al. ${ }^{18}$ demonstrate that two thirds of characteristics of outstanding clinical teachers are "noncognitive" and that, "Perhaps what makes a clinical educator truly great depends less on the acquisition of cognitive skills such as medical knowledge and formulating learn- ing objectives, and more on inherent, relationship-based, noncognitive attributes. Whereas cognitive abilities generally involve skills that may be taught and learned, albeit with difficulty, noncognitive abilities represent personal attributes, such as relationship skills, personality types, and emotional states, which are more difficult to develop and teach." 18 Our study, thus, adds to the literature by (1) highlighting examples of techniques and behaviors that encompass the crucial "noncognitive" arena and (2) informing best practices in teaching clinical medicine, especially those that resonate with learners, for future faculty development.

The findings highlight the role that relationships play in the teaching and learning of team-based medicine. Building rapport and sustaining successful relationships are cornerstones of effective teaching. ${ }^{18}$ For the attendings in this study, this manifested in observable, tangible behaviors such as greeting others by name, joking, using physical touch, and actively involving all team members, regardless of role or level of education. Previous literature has highlighted the importance of showing interest in learners. ${ }^{7,19,25-27}$ This study provides multiple and varied examples of ways in which interest might be displayed.

For patients, the critical role of relationships was evidenced through rapport building and attention to patients as people outside their acute hospitalization. For instance, attendings regularly put patients' medical issues into context and anticipated future outpatient challenges. To the authors' knowledge, previous scholarship has not significantly emphasized this form of contextualized medicine, which 
involves the mindful consideration of the ongoing needs patients may experience upon transitions of care.

Several participants highlighted humility as an important characteristic of effective clinician educators. Attendings recognized that the field produces more new knowledge than can possibly be assimilated and that uncertainty is a mainstay of modern medical care. Attendings frequently utilized self-deprecation to acknowledge doubt, a technique that created a collaborative environment in which learners also felt safe to ask questions. These findings support the viewpoints by Reilly and Beckman that humility and an appreciation for questions and push-back from learners encourage lifelong learning through role modeling. ${ }^{19,23}$ In responding to the interviewer's question "And what happens when [the attending] is wrong?" one learner simply stated, "He makes fun of himself."

This study has several limitations. First, it was conducted in a limited number of US based healthcare systems. The majority of institutions represented were larger, research intensive hospitals. While these hospitals were purposefully selected to provide a range in geography, size, type, and access to resources, the findings may differ in other settings. Second, it was conducted with a limited number of attendings and learners, which may limit the study's generalizability. However, enough interviews were conducted to reach data saturation. ${ }^{15}$ Because evidence for a causal relationship between quality teaching and student and patient outcomes is lacking, ${ }^{18}$ we must rely on imperfect proxies for teaching excellence, including awards and recognition. This study attempted to identify exemplary educators through various means, but it is recognized that bias is likely. Third, because attendings provided lists of former learners, selection and recall biases may have been introduced, as attendings may have more readily identified former learners with whom they formed strong relationships. Fourth, focus was placed exclusively on teaching and learning within general medicine rounds. This was because there would be ample opportunity for teaching on this service, the structure of the teams and the types of patients would be comparable across sites, and the principal investigator was also a general medicine attending and would have a frame of reference for these types of rounds. Due to this narrow focus, the findings may not be generalizable to other subspecialties. Fifth, attendings were selected through a nonexhaustive method. However, the multisite design, the modified snowball sampling, and the inclusion of several types of institutions in the final participant pool introduced diversity to the final list. Finally, although we cannot discount the potential role of a Hawthorne effect on our data collection, the research team did attempt to mitigate this by standing apart from the care teams and remaining unobtrusive during observations.

Using a combination of interviews, focus group discussions, and direct observation, we identified consistent techniques and behaviors of excellent teaching attendings during inpatient general medicine rounds. We hope that all levels of clinician educators may use them to elevate their own teaching.
Disclosure: Dr. Saint is on a medical advisory board of Doximity, a new social networking site for physicians, and receives an honorarium. He is also on the scientific advisory board of Jvion, a healthcare technology company. Drs. Houchens, Harrod, Moody, and Ms. Fowler have no conflicts of interest.

\section{References}

1. Accreditation Council for Graduate Medical Education. Common program requirements. 2011. http://www.acgme.org/Portals/0/PDFs/Common_Program_Requirements_07012011[2].pdf. Accessed September 16, 2016

2. Healthcare Cost and Utilization Project. Overview statistics for inpatient hospital stays. HCUP Facts and Figures: Statistics on Hospital-Based Care in the United States, 2009. Rockville, MD: Agency for Healthcare Research and Quality; 2011.

3. Busari JO, Weggelaar NM, Knottnerus AC, Greidanus PM, Scherpbier AJ. How medical residents perceive the quality of supervision provided by attending doctors in the clinical setting. Med Educ. 2005;39(7):696-703.

4. Smith CA, Varkey AB, Evans AT, Reilly BM. Evaluating the performance of inpatient attending physicians: a new instrument for today's teaching hospitals. J Gen Intern Med. 2004;19(7):766-771

5. Elnicki DM, Cooper A. Medical students' perceptions of the elements of effective inpatient teaching by attending physicians and housestaff. J Gen Intern Med. 2005;20(7):635-639.

6. Buchel TL, Edwards FD. Characteristics of effective clinical teachers. Fam Med. 2005;37(1):30-35.

7. Guarino CM, Ko CY, Baker LC, Klein DJ, Quiter ES, Escarce JJ. Impact of instructional practices on student satisfaction with attendings' teaching in the inpatient component of internal medicine clerkships. J Gen Intern Med. 2006;21(1): 7-12.

8. Irby DM. How attending physicians make instructional decisions when conducting teaching rounds. Acad Med. 1992;67(10):630-638

9. Beckman TJ. Lessons learned from a peer review of bedside teaching. Acad Med. 2004;79(4):343-346.

10. Wright SM, Carrese JA. Excellence in role modelling: insight and perspectives from the pros. CMAJ. 2002;167(6):638-643.

11. Castiglioni A, Shewchuk RM, Willett LL, Heudebert GR, Centor RM. A pilot study using nominal group technique to assess residents' perceptions of successful attending rounds. J Gen Intern Med. 2008;23(7):1060-1065.

12. Bergman K, Gaitskill T. Faculty and student perceptions of effective clinical teachers: an extension study. J Prof Nurs. 1990;6(1):33-44.

13. Richards L, Morse J. README FIRST for a User's Guide to Qualitative Methods. 3rd ed. Los Angeles, CA: SAGE Publications, Inc.; 2013.

14. U.S. News and World Report. Best Medical Schools: Research. 2014. http:// grad-schools.usnews.rankingsandreviews.com/best-graduate-schools/top-medical-schools/research-rankings. Accessed September 16, 2016.

15. Guest G, Bunce A, Johnson L. How many interviews are enough? An experiment with data saturation and variability. Field Methods. 2006;18(1):59-82.

16. Braun V, Clarke V. Using thematic analysis in psychology. Qual Res Psychol. 2006;3(2):77-101.

17. Aronson J. A pragmatic view of thematic analysis. Qual Rep. 1995;2(1):1-3.

18. Sutkin G, Wagner E, Harris I, Schiffer R. What makes a good clinical teacher in medicine? A review of the literature. Acad Med. 2008;83(5):452-466.

19. Beckman TJ, Lee MC. Proposal for a collaborative approach to clinical teaching. Mayo Clin Proc. 2009;84(4):339-344

20. Ramani S. Twelve tips to improve bedside teaching. Med Teach. 2003;25(2): 112-115.

21. Irby DM. What clinical teachers in medicine need to know. Acad Med. 1994;69(5):333-342.

22. Wiese J, ed. Teaching in the Hospital. Philadelphia, PA: American College of Physicians; 2010.

23. Reilly BM. Inconvenient truths about effective clinical teaching. Lancet. 2007;370(9588):705-711

24. Branch WT Jr, Kern D, Haidet P, et al. The patient-physician relationship. Teaching the human dimensions of care in clinical settings. JAMA. 2001;286(9): 1067-1074

25. McLeod PJ, Harden RM. Clinical teaching strategies for physicians. Med Teach. 1985;7(2):173-189.

26. Pinsky LE, Monson D, Irby DM. How excellent teachers are made: reflecting on success to improve teaching. Adv Health Sci Educ Theory Pract. 1998;3(3): 207-215.

27. Ullian JA, Bland CJ, Simpson DE. An alternative approach to defining the role of the clinical teacher. Acad Med. 1994;69(10):832-838 